\title{
Influência das precipitações na produtividade agrícola no Estado da Paraíba ${ }^{1}$
}

\author{
Lindenberg L. da Silva², Rafael F. da Costa ${ }^{2}$, João H. B. da C. Campos² \& Renilson T. Dantas²
}

\section{RESUMO}

Neste estudo, real izado em quatro microrregiões da Paraíba no período de 1990 a 2005, objetivou-se determinar as correlações entre as precipitações pluviais durante a safra para as culturas de cana-de-açúcar e abacaxi, nas microrregiões do Litoral e Brejo, e as correlações entre as precipitações durante o período chuvoso e as produtividades de algodão herbáceo, na microrregião do Sertão e do sisal, no Cariri/Curimataú. 0 s testes realizados com as equações de regressões polinomiais utilizando-se apenas a precipitação pluvial da pré-estação chuvosa ou do período chuvoso como variável independente, não foram suficientes para estimar a produtividade da cana-de-açúcar no Litoral, vez que pequenos volumes de precipitação não suprem as necessidades hídricas da cultura. A produtividade do abacaxi não mostrou correlações significativas com as precipitações pluviais nas microrregiões do Litoral e Brejo. 0 btiveram-se fortes correlações entre as precipitações pluviais durante o período chuvoso e as produtividades de algodão herbáceo no Sertão paraibano e, para o sisal no Cariri/Curimataú. Com a estimativa da precipitação durante o período chuvoso poder-se-á decidir plantar, ou não, em determinada microrregião.

Palavras-chave: abacaxi, algodão herbáceo, cana-de-açúcar, sisal

\section{Influence of precipitations on agricultural productivity in Paraíba State}

\begin{abstract}
This study was carried out in four homogeneous pluviometric micro regions of Paraíba State between 1990 and 2005. The aims were to determine the relationships between crops of sugar-cane and pineapple productivity and production season rainfall in the Litoral and 'Brejo' micro regions, the relationships between the rainy season precipitations and herbecious cotton productivity in the Sertão, and sisal in the Cariri/Curimataú micro regions. Tests accomplished with polinomial regression equations, using only early rainy season or rainy season as the independent variable were not sufficient to estimate sugar-cane productivity in the Litoral, therefore small rainfall quantities do not supply the crop water contents. Pineapple productivity did not present significant correlations with rainfall in Litoral and 'Brejo' micro regions. Strong correlations were obtained between the rainy season precipitations and the herbecious cotton productivity in the 'Sertão', and with sisal in the Cariri/Curimataú. With the estimated precipitation values during the rainy season one could decide to plant, or not, in a particular micro region.
\end{abstract}

Key words: pineapple, herb cotton, sugarcane, sisal

\footnotetext{
1 Parte da Dissertação de Mestrado em Meteorologia, do primeiro autor

2 UACA/U FCG. Av. A prígio Veloso, 882 Bloco CL, Bodocongó, Campina Grande, PB, CEP 58109-970, Fone (83) 3310 1054. E-mail: begagc@hotmail.com.br; rfcostampeg@gmail.com; jhugocampos@yahoo.com.br; renilson@dca.ufcg.edu.br
} 


\section{INTRODUÇÃO}

A variabilidade climática deve ser considerada em diversos setores, como economia, pecuária, engenharia e produção de energia. A agricultura não é apenas responsável por grande parte das exportações brasileiras e pela geração de milhares de empregos mas também uma das atividades mais vulneráveis às mudanças climáticas. Os sistemas agrícolas regionais podem ser afetados, com sérias conseqüências para a produção de alimentos.

O problema da irregularidade pluviométrica no Nordeste do Brasil (NEB) resulta não só da variação dos totais pluviométricos mas, principalmente, da duração e intensidade dessas precipitações. Em virtude dessa irregularidade climática, grandes extensões do NEB são submetidas periodicamente aos efeitos das secas que ocasionam o êxodo rural, enfraquecendo ainda mais a economia local.

As estiagens prolongadas ou as chuvas em excesso por períodos seguidos, em várias partes do mundo, incluindo a Paraíba, estão associadas aos fenômenos de escala global, como o El Niño e La Niña, que afetam a circulação geral da atmosfera.

A produtividade de culturas em sistema de sequeiro é altamente dependente das interações entre suas fases fenológicas e as variações interanuais do tempo e clima. Toda cultura plantada nesse sistema depende, inevitavelmente, da quantidade, da distribuição e da intensidade das chuvas. Por outro lado, os fenômenos El Niño e Dipolo influenciam os totais pluviométricos do Nordeste brasileiro; em consequiência, contribuem nas variações do rendimento das culturas de subsistência (Silva et al, 2002).

Segundo IPPC (2001), a produtividade agrícola no Brasil depende do clima e sua variabilidade. Esta dependência é importante durante o ciclo de vida das culturas, além de responsável pela alternância das produções agrícolas anuais, $o$ que, sem dúvida, influencia diretamente no balanço da produção, ocorrendo perda ou ganho em função das condições climáticas de uma região; um exemplo disso é o balanço percentual da produção de cereais na América do Sul, que ganha cerca de trinta milhões de $\mathrm{t}^{\mathrm{ano}} \mathrm{o}^{-1}$; dos seus doze países, seis perdem mais de sessenta milhões de $\mathrm{t}$ e outros ganham noventa milhões. O Brasil, que representa metade da população da região, perde $14 \%$ da produção de grãos.

O consumo de água pelas comunidades vegetais é uma informação relevante no planejamento agrícola, com vistas à avaliação da produtividade das culturas (Campos et al., 2008). As necessidades hídricas das culturas agrícolas precisam ser satisfeitas nos diversos estádios fenológicos, desde a germinação e estabelecimento da cultura, passando pelo desenvolvimento, floração, formação e crescimento dos grãos ou frutos, até atingir a maturação e a colheita. No cultivo agrícola é imprescindível se conhecer as relações entre as chuvas da pré-estação e período chuvoso para escolha da melhor época de semeadura, devido às condições hídricas do solo, visto que, principalmente no Nordeste, antes da pré-estação chuvosa sempre há um período de estiagem que reduz bastante o conteúdo de água no solo disponível para as plantas.
Objetivou-se, neste trabalho, correlacionar as precipitações pluviais com a produtividade em quatro microrregiões da Paraíba, no período de 1990 a 2005; levantar a precipitação da safra com a produtividade da cana-de-açúcar no Litoral, precipitações da pré-estação com a produtividade do abacaxi no Litoral e no Brejo, e as precipitações do período chuvoso com as produtividades do algodão herbáceo e sisal, no Sertão e no Cariri/Curimataú, respectivamente.

\section{MATERIAL E MÉTODOS}

Para se estudar as relações entre precipitação pluvial e a produtividade agrícola em microrregiões da Paraíba, utilizaramse informações de produções anuais de cana-de-açúcar, abacaxi, algodão herbáceo e sisal, no período de 1990 a 2005; os dados pluviométricos foram obtidos em 66 postos, no período de 1975 a 2005, nas seis microrregiões pluviometricamente homogêneas da Paraíba (6 $6^{\circ} 02^{\prime}-8^{\circ} 30^{\prime}$ Sul; 34 79' - $38^{\circ} 77^{\prime}$ Oeste) que são, Litoral, Brejo, Agreste, Cariri/Curimataú, Sertão e Alto Sertão (AESA, 2007; IBGE, 2007).

A avaliação da variabilidade climática ao longo do tempo em uma região, identifica a ocorrência de alterações contínuas ou ciclos de elementos meteorológicos, como chuva ou temperatura. Calcularam-se, no desenvolvimento deste estudo, correlações e se utilizou a técnica estatística de regressão polinomial (Rao \& Hada, 1990; Rao et al., 1993; 1997), visando analisar a relação da precipitação pluvial com a produtividade agrícola das seguintes culturas; cana-de-açúcar no Litoral, abacaxi no Litoral e no Brejo, sisal no Cariri/ Curimataú e algodão herbáceo no Sertão.

As correlações foram obtidas pelas equações de regressão polinomial de terceira ordem, utilizadas entre as precipitações da pré-estação (PE) do período chuvoso (PC) com a produtividade agrícola de cada microrregião da Paraíba; para a correlação entre o PC e a produtividade agrícola das culturas, $\mathrm{N}$ é o tamanho da amostra; $(\mathrm{N}-2)$ corresponde ao grau de liberdade da amostra $(\mathrm{N}=15$ anos de dados) e 13 é o grau de liberdade; então, os valores tabelados do teste estatístico $\mathrm{T}$ de Student (t) e o coeficiente de correlação crítico $\left(\mathrm{r}_{\mathrm{c}}\right)$ são para $99 \%$ de significância, ou seja, com erro de $1 \%(\mathrm{a}=0,01)$, $\mathrm{t}=2,947 ; \mathrm{r}_{\mathrm{c}}=0,632$, e para $95 \%$ de significância, ou erro de $5 \%(\mathrm{a}=0,05), \mathrm{t}=2,131$ e $\mathrm{r}_{\mathrm{c}}=0,508$ (Silva, 2007).

Neste trabalho se considerou, como período chuvoso (PC) o conjunto dos sete meses com os maiores totais mensais de precipitação pluvial. Dentro do PC foram divididas duas épocas distintas, ou seja, a pré-estação chuvosa (PE) representada pelos três meses iniciais do PC, e a estação chuvosa (EC) ou quadra chuvosa que são os quatro meses restantes do PC (Silva, 2007; Silva et al., 2004).

Os postos pluviométricos que representaram a microrregião do Litoral paraibano, foram: Alhandra, Cruz do Espírito Santo e Mamanguape. Os postos do Brejo foram: Alagoa Grande, Alagoa Nova, Araçagí, Areia, Bananeiras, Caiçara, Sapé e Serraria; no Agreste, foram: Acaú, Araruna, Aroeiras, Cacimba de Dentro, Fagundes, Pilar, Salgado e Umbuzeiro; no Cariri/Curimataú, foram: Barra de Santana, Cabaceiras, Camalaú, Caraúbas, Coxixola, Gurjão, Olivedos, Pedra Lavrada, 
Pocinhos, Prata, Riacho de Santo Antonio, Salgadinho, Santa Maria da Paraíba, Seridó, Soledade, Sossego, São João do Tigre, São José dos Cordeiros e São Sebastião do Umbuzeiro. Os postos do Sertão, foram: Água Branca, Brejo do Cruz, Imaculada, Jenipapeiro dos Carreiros, Jericó, Mãe D'água, Malta, Passagem, São Francisco, São Mamede, Santa Luzia, Santa Terezinha e Uiraúna; para o Alto Sertão, foram: Aguiar, Bonito de Santa Fé, Cajazeiras, Conceição, Ibiara, Juru, Manaíra, Nazarezinho, Olho D'água, Princesa Isabel, São João do Rio do Peixe, São José da Lagoa Tapada, São José de Piranhas, Santana dos Garrotes e Serra Grande (Figura 1).

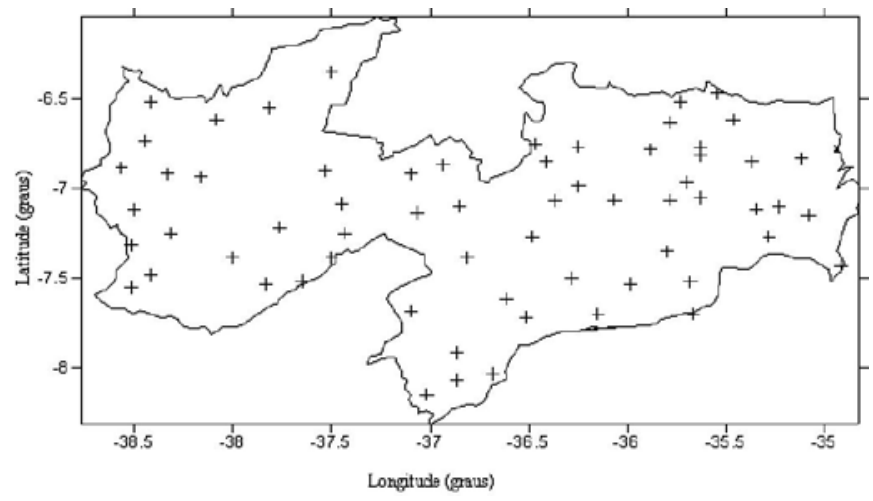

$\overline{\text { Figura 1. Distribuição espacial dos postos pluviométricos do estado da Paraíba }}$ utilizados neste estudo

\section{RESULTADOS E DISCUSSÃO}

\section{Microrregiões pluviometricamente homogêneas da Paraíba}

A divisão realizada por Silva et al. (2004) classificou a Paraíba em seis microrregiões pluviometricamente homogêneas, as quais são: Litoral, Brejo, Agreste, Cariri/Curimataú, Sertão e Alto Sertão, que apresentaram diferentes épocas de préestação e estação chuvosa (Tabela 1).

O litoral foi a microrregião do estado que apresentou o maior total médio de precipitação anual (PA) com $1468 \pm 429,2$ $\mathrm{mm} \mathrm{a}^{-1}$, enquanto o total da EC foi de 765,8 $\pm 285,3 \mathrm{~mm} \mathrm{a}^{-1}$.

O Brejo apresentou uma PA de $1123,5 \pm 321,4 \mathrm{~mm} \mathrm{a}^{-1}$ ou $76,5 \%$ da precipitação da microrregião do Litoral que tem a mesma época da EC; entretanto, enquanto para o Litoral o total de precipitação da EC foi de 52,2\% da PA, no Brejo as chuvas da EC corresponderam a 48,8\% da PA.

A microrregião do Agreste é pluviometricamente diferenciada do Brejo e Litoral; apesar de apresentar a mesma época de EC, ela apresenta PA inferior, com média de 728,1 $\pm 238,5$ $\mathrm{mm} \mathrm{a}^{-1}$, aproximadamente $65 \%$ da precipitação do Brejo e 49,6\% da precipitação do Litoral, porém o total médio de chuva durante a $\mathrm{EC}$ é de $50 \%$ da $\mathrm{PA}$, ou seja, próximo à relação encontrada para o Litoral (52\% da PA); tanto a microrregião do Agreste como o Litoral e o Brejo, apresentou o trimestre mais chuvoso entre maio e julho (Menezes et al., 2003; Silva, 2004).

A microrregião do Cariri/Curimataú tem a sua EC no período de fevereiro, registrando $265,4 \pm 158,7 \mathrm{~mm} \mathrm{a}^{-1}$ representando $56,7 \%$ da PA.

Apesar de o Sertão apresentar a mesma EC do Cariri/Curimataú, a região é caracterizada por ter PA de aproximadamente 730,4 $\pm 290,4 \mathrm{~mm}^{2} \mathrm{no}^{-1}$, que é próximo ao observado para o Agreste $(728,1 \mathrm{~mm})$; no entanto, a semelhança é apenas na PA, visto que a EC do Sertão vai de fevereiro a maio e a do Agreste de maio a agosto. A precipitação da EC no Sertão corresponde a 63,2\% da PA, enquanto no Agreste é de 50\%, destacando-se a maior concentração temporal das precipitações no Sertão, deixando a região mais dependente das chuvas ocorridas na EC para a reposição de água no solo, que servirá para o desenvolvimento da cultura implantada na área.

A microrregião do Alto Sertão apresentou a EC de fevereiro a maio e registrou uma PA de $924,9 \pm 296,5 \mathrm{~mm}^{2}$ ano ${ }^{-1}$, sendo que $61,2 \%$ deste valor foram atribuídos à precipitação da $\mathrm{EC}$, repetindo a dependência das precipitações verificadas nessa época do ano, no Sertão.

Destaca-se que cinco das seis microrregiões analisadas registraram períodos chuvosos (PC) que concentraram mais de $80 \%$ das precipitações anuais; a exceção foi o Cariri/Curimataú, que teve PC de 70,1\% da PA; o Agreste foi a área com a maior relação, sendo $\mathrm{PC}$ de $85,8 \%$ da PA, indicando forte concentração das chuvas nos sete meses do ano, o que provoca uma estiagem de pelo menos cinco meses sem chuvas de grande quantidade.

\section{A participação da Paraíba na produção de cana-de-açúcar do Brasil}

Importante cultura agrícola para o Brasil desde o período da colonização pelos europeus, ainda no século XVI, a canade-açúcar tem significativo peso econômico para o País, maior produtor mundial. Em 2005, o Brasil colheu uma safra de 423 milhões de $t$ de cana-de-açúcar, distribuída em diversas regiões brasileiras, principalmente no Sudeste e no Nordeste (Figura 2A).

Na Paraíba, a agricultura canavieira se estende por diversas áreas na parte Leste do Estado. Neste estudo foram consideradas seis sub-regiões: Litoral Norte (Ln), João Pessoa (JP), Litoral Sul (Ls), Guarabira (Gb), Sapé (Sp) e Brejo paraibano $(\mathrm{Bj} \mathrm{Pb})$. As sub-regiões do Ls, Sp e Ln, são as mais im-

Tabela 1. Precipitações médias e desvios-padrão $(\mathrm{mm})$ da pré-estação chuvosa (PE), estação chuvosa (EC), e precipitação total anual (PA) para as microrregiões pluviometricamente homogêneas da Paraíba, no período de 1975 a 2005

\begin{tabular}{ccccccc}
\hline & Litoral & Brejo & Agreste & Cariri/Curimataú & Sertão & Alto Sertão \\
PE & & Fevereiro a Abril & & Novembro a J aneiro \\
& $450,0 \pm 175,3$ & $377,7 \pm 160,1$ & $260,3 \pm 134,2$ & $62,3 \pm 59,4$ & $124,6 \pm 84,8$ & $202,2 \pm 101,7$ \\
\hline \multirow{3}{*}{ EC } & Maio a Agosto & & Fevereiro a Maio & \\
& $765,8 \pm 285,3$ & $548,3 \pm 161,6$ & $364,1 \pm 115,3$ & $265,4 \pm 158,7$ & $461,1 \pm 199,0$ & $566,1 \pm 179,5$ \\
PA & $1468,0 \pm 429,2$ & $1123,5 \pm 321,4$ & $728,1 \pm 238,5$ & $467,6 \pm 209,0$ & $730,4 \pm 290,4$ & $924,9 \pm 296,5$ \\
\hline
\end{tabular}


A.

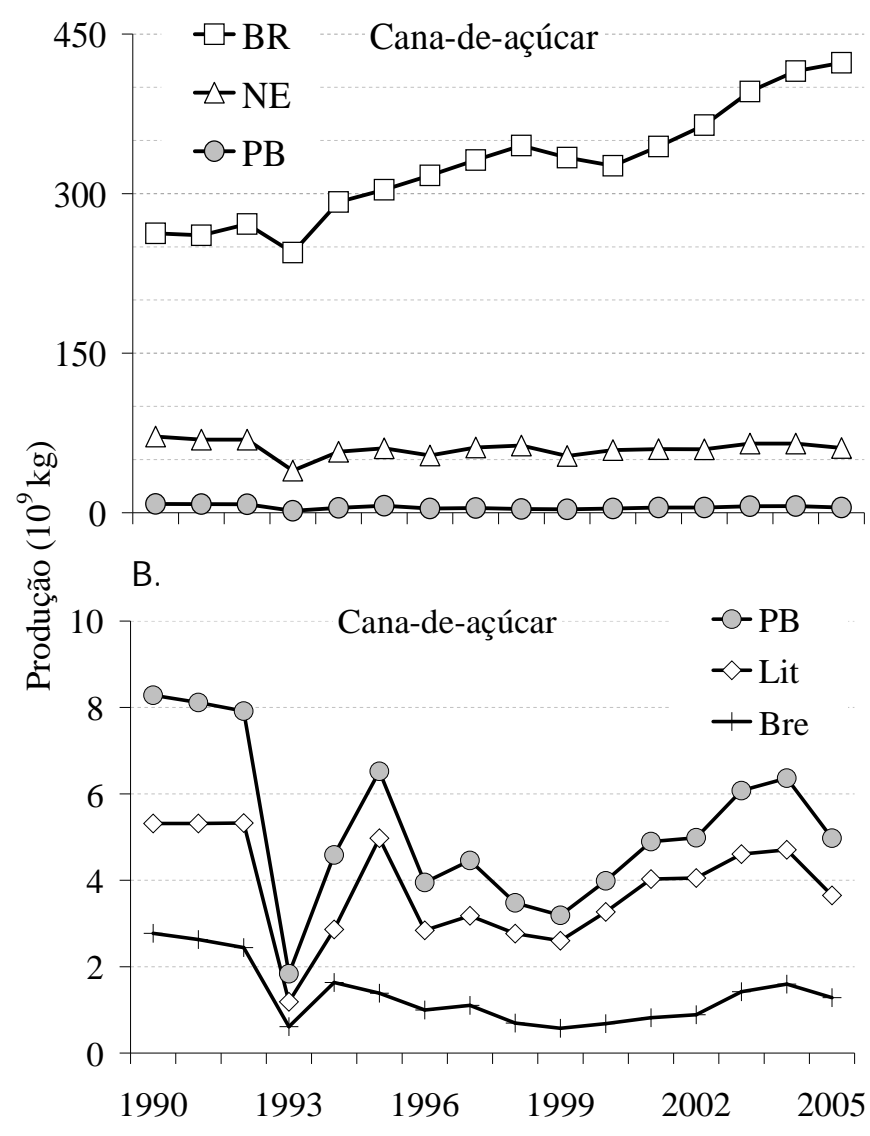

Figura 2. Produção anual de cana-de-açúcar $(\mathrm{kg})$ no período de 1990 a 2005. (A) Brasil (BR), Nordeste (NE) e Paraíba (PB) e (B) Paraíba (PB), Litoral (Lit), Brejo (Bre)

portantes do Estado, sendo que o Ln responde pela maior parte da produção paraibana; em 1993, todas as áreas foram influenciadas pelo evento El Niño, que provocou redução drástica na produção naquele ano; para uma análise melhor da produtividade de cana-de-açúcar no estado, as sub-regiões produtoras foram agrupadas em duas microrregiões, denominadas Litoral (Lit) e Brejo (Bre) sendo que o Lit foi composto pelas sub-regiões Ln, JP e Ls, enquanto o Bre foi o conjunto das sub-regiões de $\mathrm{Gb}, \mathrm{Sp}$ e $\mathrm{BjPb}$, em que as produções dessas duas microrregiões representam quase que a totalidade da produção paraibana de cana-de-açúcar (Figura 2B); em 1990, o Lit colheu cerca de 5,31 milhões de t, ou 64,2\% da produção da Paraíba, enquanto o Bre foi responsável por 2,77 milhões de t, ou 33,5\% do total do Estado; em 2001, as participações do Lit e Bre foram de 82,3 e 16,7\%, e em 2005 atingiram 73,3 e 25,8\% (3,64 e 1,28 milhões de t), respectivamente.

Relação da precipitação pluvial com a produtividade de cana-de-açúcar no Litoral da Paraíba

Para análise das relações entre a produtividade de canade-açúcar e as precipitações pluviais na Paraíba, escolheu-se a microrregião do Litoral, por representar a maior parte da produção do Estado (73,3\% em 2005).

Diferentemente das culturas com ciclos de produção curtos, de três a seis meses, a cana-de-açúcar e o abacaxi têm ciclos de produção longos, acima de doze meses; deste modo, para se relacionar a produtividade dessas culturas com as precipitações, foi necessário totalizar as precipitações pluvial durante dezesseis meses, denominada precipitação da safra (SA) abrangendo uma EC de quatro meses no ano de implantação da cultura, seguida de um período de estiagem com cinco meses, geralmente no final do ano de implantação e no início do ano da colheita, quando ocorrem precipitações esporádicas e de pequena quantidade, concluindo com o PC com sete meses no ano da colheita, que compreende uma PE com três meses e uma EC com quatro meses de duração, perfazendo o total de dezesseis meses de informações pluviométricas; referidos procedimentos foram realizados para as microrregiões do Litoral e Brejo paraibanos (Figura 3), principais áreas de cultivo da cana-de-açúcar e do abacaxi, no Estado.

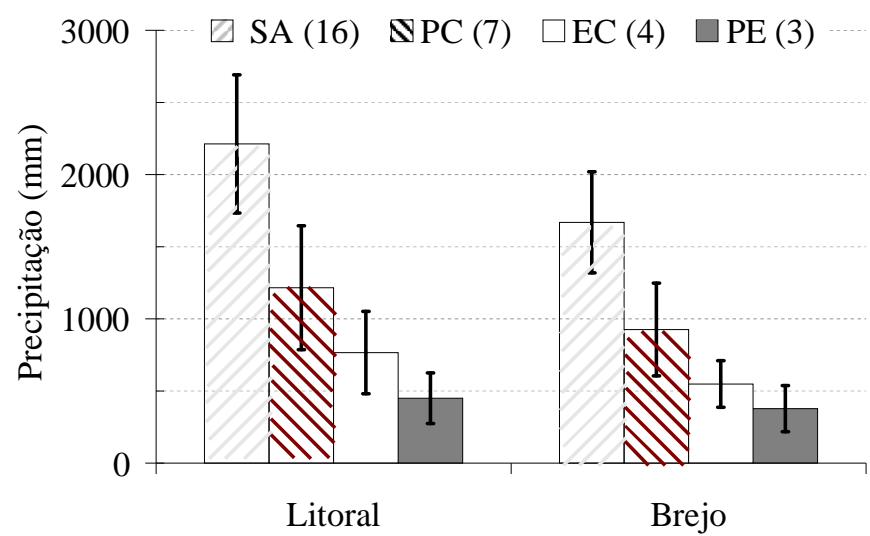

Figura 3. Precipitações (mm) da safra (SA), período chuvoso (PC), estação chuvosa (EC) e pré-estação (PE) para o Litoral e Brejo da Paraíba, médias de 1975 a 2005. Entre parênteses os meses de duração de cada período. As linhas verticais são os desvios-padrão

Apesar da produção de cana-de-açúcar na Paraíba ter diminuído nos últimos dezesseis anos (1990-2005), a tendência da produtividade é de recuperação, embora com leve crescimento. No início da década de 1990 a produtividade paraibana foi de 52,3 tha-1 no ano de 1991; após grandes oscilações durante o período, a produtividade voltou a atingir valores melhores em 2003 e 2004, quando foram registradas 54,4 e 54,5 $\mathrm{t} \mathrm{ha}^{-1}$, respectivamente; em 2005, a produtividade na Paraíba chegou a 47,2 $\mathrm{t} \mathrm{ha}^{-1}$; no ano de 1993, a redução foi geral, tanto na produção como na área cultivada no Estado; concomitantemente, ocorreu a influência de um evento de El Niño, resultando em queda abrupta da produtividade, de 51,6 $\mathrm{t} \mathrm{ha}^{-}$ ${ }^{1}$ em 1992, para 19,8 $\mathrm{t} \mathrm{ha}^{-1}$. A estiagem prolongada provocada pela anomalia do El Niño, em 1993, causou quebra nas safras paraibana e nacional. Pela classificação de eventos de El Niño e La Niña do INPE/CPTEC (2005) o ano de 1993 foi de El Niño forte, enquanto 1994 foi de El Niño moderado. A condição de estresse hídrico resultou em plantas de menor porte e baixa qualidade, refletindo na produtividade. A situação da cultura canavieira paraibana começou a se recuperar a partir de 1999, quando tanto a área plantada como a produção experimentaram crescimento refletindo na melhoria da produtividade observada nos anos seguintes, até 2004 . Os valores da produtividade da cana-de-açúcar ( $\left.\mathrm{t} \mathrm{ha}^{-1}\right)$ e da precipitação pluvial 
(mm) para os dezesseis meses considerados de safra, na microrregião do Litoral paraibano, apresentaram variações proporcionais no período analisado (1991-2005), principalmente de 1991 a 2000. A redução considerável da produtividade observada no ano de 1993, como já discutido, foi causada pela ocorrência de um forte evento de El Nino que provocou diminuição na precipitação. $O$ total de precipitação não parece muito pequeno haja vista que considera as precipitações ocorridas durante os dezesseis meses da safra, de maio de um ano até agosto do ano seguinte (Figura 4).

Calcularam-se, para determinar a correlação entre a preci-

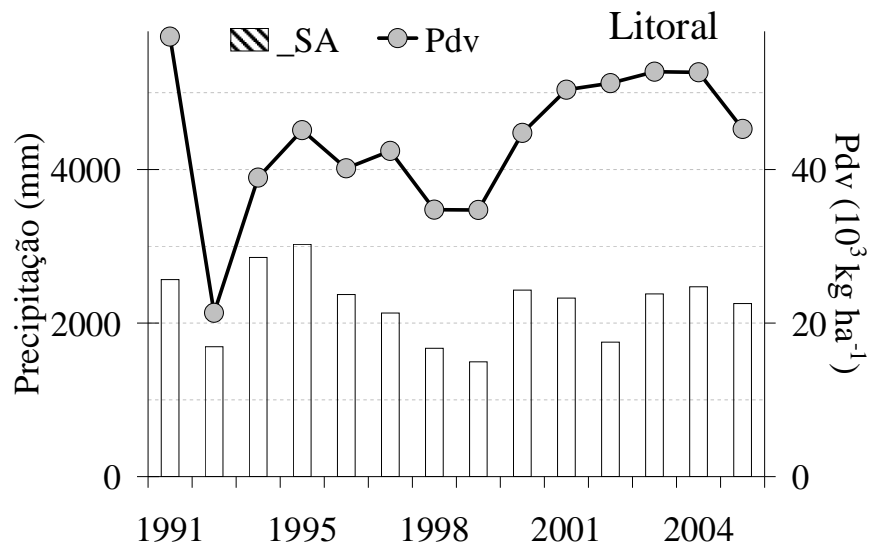

Figura 4. Produtividade (Pdv) anual de cana-de-açúcar $\left(\mathrm{kg} \mathrm{ha}^{-1}\right)$ no Litoral, e a precipitação (mm) durante a safra (SA) no período de 1990 a 2005

pitação pluvial e a produtividade de cana-de-açúcar: a quantidade de água precipitada durante toda a safra e que estaria disponível para as plantas, e a produtividade, que é o resultado da divisão da produção pela área plantada. O coeficiente $(r=0,65)$ indicou correlação moderada entre a precipitação durante a safra e a produtividade de cana-de-açúcar no Litoral paraibano; desta maneira, seria possível estimar a produtividade dessa microrregião, com uma confiabilidade regular, através da seguinte equação de regressão polinomial de terceira ordem; Pdv $=-2 \times 10^{-08} \mathrm{SA}^{3}+0,0001 \mathrm{SA}^{2}-0,2332 \mathrm{SA}+171,85$ (Tabela 2) utilizando-se apenas da informação da precipitação; esta correlação indicou que seria necessário um volume de água disponível para a cana-de-açúcar, em torno de $6,0 \mathrm{~mm}$ $\mathrm{d}^{-1}$, durante o período da safra que, nesse estudo, foi de 16 meses, para se obter uma produtividade, por volta de $50 \mathrm{t} \mathrm{ha}^{-}$ 1. Os testes realizados com modelos matemáticos nos quais se utilizou apenas a precipitação da PE ou do PC como variável independente, não foram suficientes para estimar a produtividade da cana-de-açúcar no litoral paraibano, vez que pequenas quantidades acumuladas de precipitação não suprem as necessidades hídricas da cultura.

\section{A participação da Paraíba na produção de abacaxi do Brasil}

Entre as culturas implantadas no Brasil, a do abacaxi se tem destacado na atualidade, sobretudo nas regiões Norte e Nordeste, particularmente na Paraíba. O abacaxi tem aumentado sua produção constantemente nos últimos quinze anos no Brasil; a adaptação das novas variedades desenvolvidas aos diferentes tipos de solo e clima brasileiros favorece este crescimento. Em 2005, o Brasil colheu uma safra de mais de 1,5 bilhão de frutos; o Nordeste foi responsável por cerca de 665 milhões de frutos ou cerca de $44 \%$ da produção brasileira; a Paraíba tem papel importante na produção nacional de abacaxi e foi responsável por mais de 325 milhões de frutos, que representaram cerca de $21,3 \%$ do total produzido no Brasil (Figura 5A).

Desde o início da década de 1990 a Paraíba se destacou na produção nacional, com uma pequena redução da quantidade na safra de 1996, devido aos problemas tributários no Estado. No início dos anos 90 a produção paraibana representava quase $40 \%$ do total nacional ou aproximadamente trezentos milhões de frutos; esta participação, por sua vez, foi sendo reduzida gradativamente durante os anos subseqüentes, até atingir a menor representatividade em 1997, quando ficou abaixo de dez por cento do total brasileiro; depois dessa época de queda, a produção paraibana retomou o crescimento porém não conseguiu mais acompanhar o ritmo da produção de alguns outros Estados brasileiros e sua participação na produção nacional reduziu; apesar de sua participação ter reduzido no total da produção nacional entre 1990 e 2005, a Paraíba conseguiu aumentar a produção local de abacaxi, no mesmo período; este crescimento é reflexo da produtividade estadual que também melhorou durante o período, saindo de mais de vinte e dois mil frutos por hectare em 1990, caindo para cerca de dezessete mil frutos por hectare em 1996 e retomando o crescimento, até alcançar a marca de 29.300 frutos ha ${ }^{-1} \mathrm{em} 2005$.

A abacaxicultura se desenvolve em cinco sub-regiões paraibanas: Litoral Norte (Ln), João Pessoa (JP), Litoral Sul (Ls), Guarabira (Gb) e Sapé (Sp). As sub-regiões do Ln, JP e Gb foram as maiores produtoras de abacaxi da Paraíba em 2005; historicamente, o Ln respondeu pela maior parte da produção paraibana. No início da década de 1990 as sub-regiões Ln e Sp produziam, em conjunto, cerca de duzentos milhões de frutos, porém em 1996 sofreram redução drástica na produção, em razão da taxação tributária imposta pelo Estado nesse ano, e em 1997 a produção paraibana ficou reduzida;

Tabela 2 Modelos matemáticos obtidos pelas regressões polinomiais de terceira ordem entre as precipitações durante a Safra (SA), no período chuvoso (PC), e pré-estação (PE) com a Produtividade (Pdv) de algumas culturas agrícolas na Paraíba

\begin{tabular}{ccccc}
\hline Cultura & Microrregiões & Modelos & $\mathbf{R}^{2}$ & $\mathbf{r}$ \\
Cana-de- açúcar & Litoral & $\mathrm{Pdv}=-2 \times 10-08 \mathrm{SA} 3+0,0001 \mathrm{SA2}-0,2332 \mathrm{SA}+171,85$ & 0,4186 & 0,65 \\
Abacaxi & Litoral & $\mathrm{Pdv}=5 \times 10-07 \mathrm{PE} 3-0,0007 \mathrm{PE} 2+0,2693 \mathrm{PE}-5,4239$ & 0,3841 & 0,62 \\
Abacaxi & Brejo & $\mathrm{Pdv}=1 \times 10-06 \mathrm{PE3}-0,001 \mathrm{PE} 2+0,2543 \mathrm{PE}+6,0573$ & 0,1956 & 0,44 \\
Algodão herbáceo & Sertão & $\mathrm{Pdv}=-3 \times 10-05 \mathrm{PC} 3+0,051 \mathrm{PC2}-22,257 \mathrm{PC}+2924,2$ & 0,8532 & 0,92 \\
Sisal & Cariri/Curimataú & $\mathrm{Pdv}=2 \times 10-05 \mathrm{PC}-0,0211 \mathrm{PC} 2+7,3258 \mathrm{PC}-65,295$ & 0,852 & 0,92 \\
\hline
\end{tabular}


A.

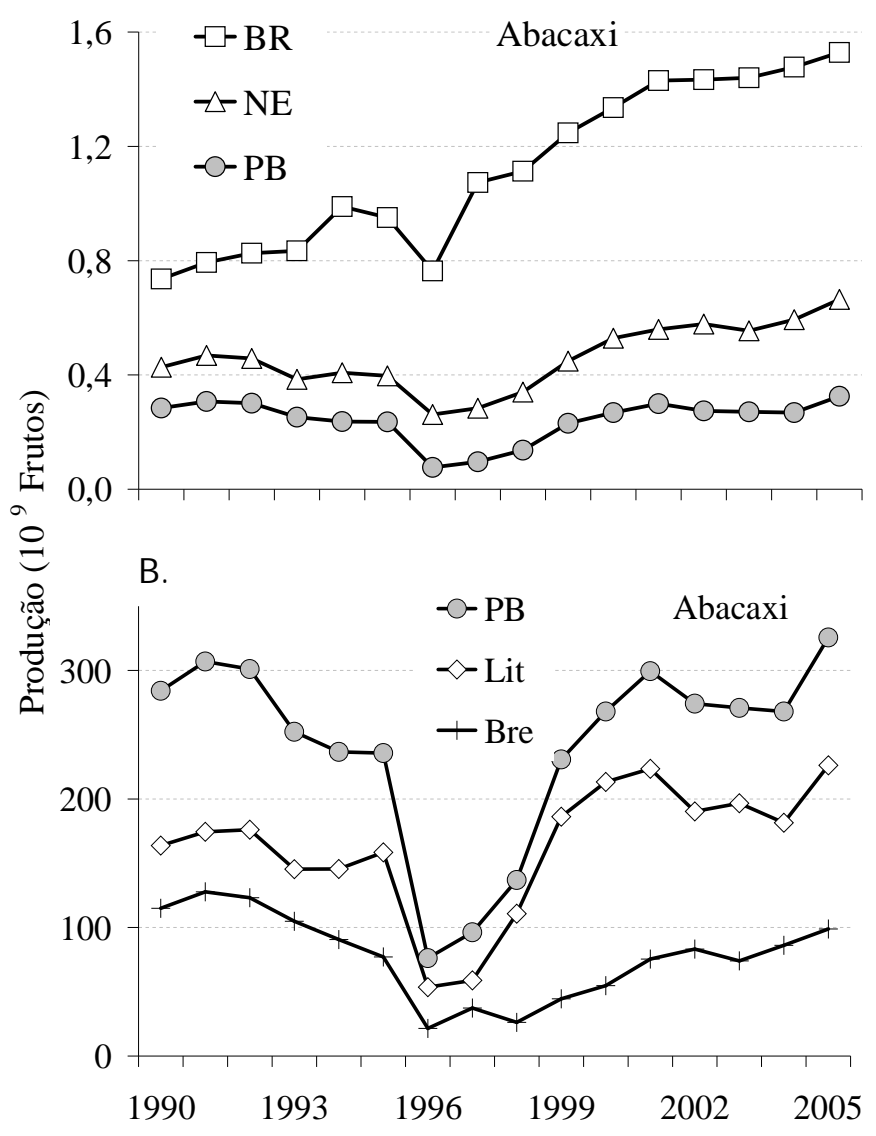

Figura 5. Produção anual de abacaxi, (A) Brasil (BR), Nordeste (NE), Paraíba (PB) em bilhões de frutos. (B) Paraíba (PB), Litoral (Lit), Brejo (Bre) em milhões de frutos, de 1990 a 2005

após esta fase, a sub-região de Sp não conseguiu recuperar sua importância no cenário da abacaxicultura na Paraíba e desde então a sub-região de JP ocupou lugar de destaque na produção paraibana chegando a ocupar o primeiro lugar entre 1998 e 2001, dividindo a liderança com o Ln, seguido de Gb em 2005. Para análise, assim como para a cana-de-açúcar, a produção paraibana de abacaxi foi agrupada em duas microrregiões, denominadas Litoral e Brejo, fazendo parte do Litoral as sub-regiões Ln, JP e Ls e, no Brejo, ficaram as sub-regiões de $\mathrm{Gb}$ e $\mathrm{Sp}$. As produções dessas duas microrregiões representam quase que a totalidade da produção paraibana de abacaxi; em 1990, o Litoral colheu cerca de 163 milhões de frutos que representaram 57,4\% da produção da Paraíba, enquanto o Brejo foi responsável por aproximadamente 115 milhões de $\mathrm{t}$ ou $40,5 \%$ do total do Estado. Na queda de produção do ano de 1996, a participação do Litoral e do Brejo foi de 53,5 e 21,3 milhões de frutos ou 70 e $28,3 \%$, respectivamente; após os anos de recuperação, a microrregião do Litoral se destacou na produção paraibana e em 2005 atingiu a marca de 226 milhões de frutos, que representaram $69,5 \%$ do total do Estado. A microrregião do Brejo produziu cerca de 99 milhões de frutos, ou 30,5\%; as duas áreas produziram, praticamente, todo o abacaxi na Paraíba (Figura 5B).

\section{Relação da precipitação com a produtividade de abacaxi no Litoral da Paraíba}

Escolheu-se a microrregião do Litoral para o estudo das relações entre a produtividade de abacaxi e as precipitações pluviais na Paraíba, em virtude dessa área representar cerca de $70 \%$ da produção do Estado. As informações referentes às precipitações no Litoral se compunham dos totais mensais de dezesseis meses, representando a safra de abacaxi, denominada precipitação da safra (SA).

Valores da produtividade do abacaxi (milhares de frutos por hectare) e da precipitação pluvial ( $\mathrm{mm}$ ) para os dezesseis meses considerados de safra, na microrregião do Litoral paraibano, não mostraram variações proporcionais entre si, no período de 1990 a 2005 (Figura 6); deste modo, as correlações entre essas variáveis indicaram resultados inexpressivos, mesmo quando testada a produtividade com as precipitações da pré-estação chuvosa (PE - 3 meses), do período chuvoso (PC - 7 meses) e anual (PA 12 meses). Para o Litoral, a equação de regressão polinomial de terceira ordem entre a produtividade e a precipitação da pré-estação, foi $\mathrm{Pdv}=5 \times 10^{-07} \mathrm{PE}^{3}-$ $0,0007 \mathrm{PE}^{2}+0,2693 \mathrm{PE}-5,4239$ com $\mathrm{R}^{2}=0,3841$, enquanto para a microrregião do Brejo a equação de regressão polinomial foi $\mathrm{Pdv}=1 \times 10^{-06} \mathrm{PE}^{3}-0,001 \mathrm{PE}^{2}+0,2543 \mathrm{PE}+6,0573$ com $\mathrm{R}^{2}=0,1956$ (Tabela 2).

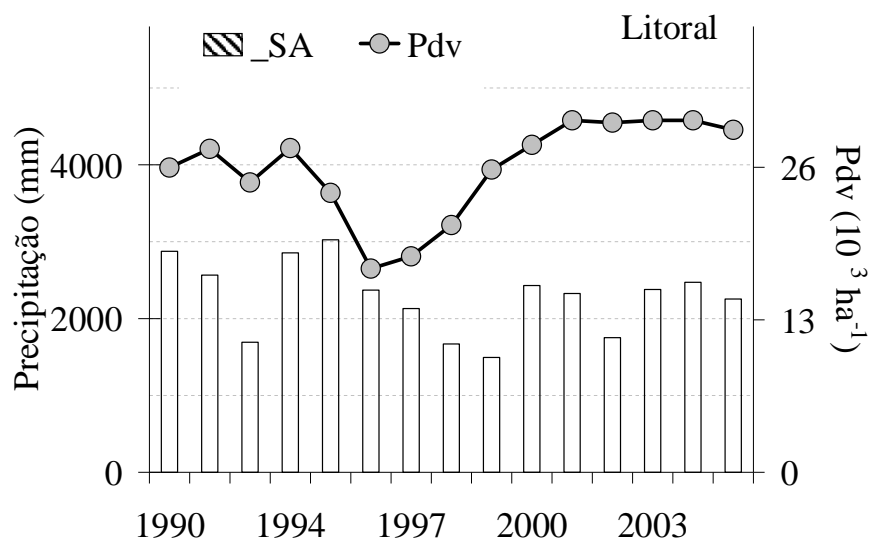

Figura 6. Produtividade (Pdv) anual de abacaxi (milhares de frutos por hectare) no Litoral da Paraíba, entre 1990 e 2005, e a precipitação pluvial (mm) durante a safra (SA)

\section{Relação da precipitação com a produtividade de algodão herbáceo na Paraíba}

O cultivo do algodão herbáceo na Paraíba se espalha pelo lado Oeste do Estado. Para essas análises se consideraram três microrregiões: o Sertão (Srt) composto de Catolé do Rocha, Cajazeiras, Souza e Patos; o Alto Sertão (ASrt) formado de Piancó e Itaporanga, e o Cariri/Curimataú (C-C). A microrregião mais importante do Estado na produção de algodão herbáceo foi o $\mathrm{Srt}$, que respondeu pela maior parte da produção (Figura 7A).

Há muita oscilação na produção anual do algodão herbáceo na Paraíba; no período de 1990 a 2005, houve quedas no total produzido nos anos de 1993 devido, provavelmente, ao forte evento de El Niño, em 1996, depois em 1998, em 2001 e 
A.

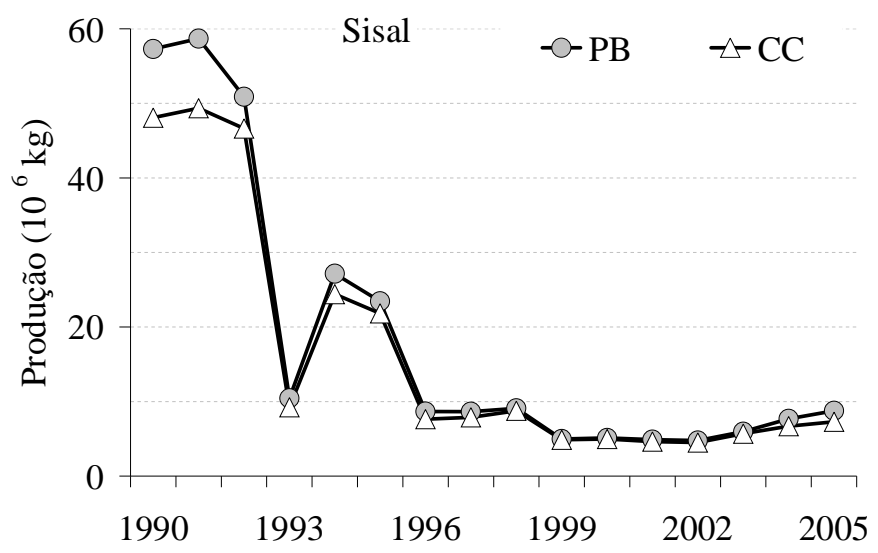

B.

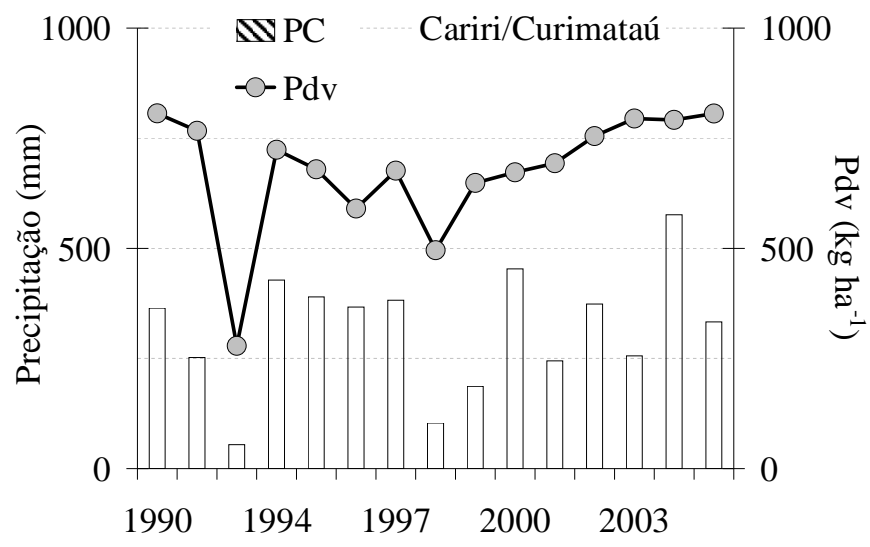

Figura 7. (A) Produção anual de algodão herbáceo $(\mathrm{kg})$ na Paraíba $(\mathrm{PB})$ no Sertão (Srt), Cariri/Curimataú (C-C), e Alto Sertão (Asrt). (B) Produtividade (Pdv) anual de algodão herbáceo $\left(\mathrm{kg} \mathrm{ha}^{-1}\right)$ no Sertão e a precipitação pluvial $(\mathrm{mm})$ durante o período chuvoso (PC) entre 1990 e 2005

2005; esses quatro ciclos de queda na produção estão associados às variações da precipitação pluvial, pois esta cultura é bastante sensível à deficiência hídrica. O fato de se tratar de uma planta de produção rápida, faz com que o algodoeiro sinta os efeitos de pequenas variações climáticas, como os períodos de alguns dias sem precipitação pluvial durante as estações chuvosas (veranicos), que prejudicam a qualidade do produto nos estádios fenológicos de maior necessidade hídrica. As informações relativas às precipitações pluviais na microrregião do Sertão, se compuseram dos totais mensais de sete meses, de dezembro a junho, representando o período chuvoso (PC). Valores da produtividade do algodão herbáceo $\left(\mathrm{kg} \mathrm{ha}^{-1}\right)$ e da precipitação pluvial $(\mathrm{mm})$ para o PC, na microrregião do Sertão paraibano, mostraram variações proporcionais entre si, no período de 1990 a 2005 (Figura 7B).

A obtenção da correlação entre a precipitação pluvial do período chuvoso $(\mathrm{PC})$ e a produtividade de algodão herbáceo, resultou em um coeficiente $(r=0,92)$ indicando forte correlação entre a precipitação, durante os sete meses do período chuvoso e a produtividade de algodão herbáceo na microrregião do Sertão paraibano; assim, é possível estimar a produtividade dessa microrregião com um bom grau de confiabilidade, através da seguinte equação de regressão poli- nomial de terceira ordem; $\mathrm{Pdv}=-3 \times 10^{-05} \mathrm{PC}^{3}+0,051 \mathrm{PC}^{2}-$ 22,257PC+2924,2 (Tabela 2), utilizando-se apenas da informação da precipitação pluvial do período chuvoso que, por sua vez, já se apresentou bem correlacionada com as precipitações dos três meses da pré-estação chuvosa; esta correlação linear indicou que seria necessário um volume de chuva em torno de 3,5 a 4,0 $\mathrm{mm} \mathrm{d}^{-1}$, ou por volta dos $800 \mathrm{~mm}$ durante o período chuvoso (210 dias), para se ter uma produtividade próxima de $1.500 \mathrm{~kg} \mathrm{ha}^{-1}$.

\section{Relação da precipitação pluvial com a produtividade de sisal na Paraíba}

Apenas a microrregião do Cariri/Curimataú produz sisal de maneira significativa na Paraíba. Houve variação da produção anual do sisal no Estado, no período de 1990 a 2005, além de uma redução acentuada dos totais anuais produzidos em 1990, 1991 e 1992, que foram da ordem de 57,3; 58,7 e 50,9 mil t, respectivamente, para cerca de 10,4 mil t em 1993, devido, sem dúvida, ao forte evento de El Niño daquele ano (Figura 8A). Nos anos de 1994 e 1995 deu-se reação na produção, que se recuperou um pouco, passando para a casa das $27,2 \mathrm{e}$ 23,5 mil t, respectivamente; depois de breve elevação, a produção de sisal na Paraíba voltou a despencar para cerca de 8,7 mil t em 1996, permanecendo nesse patamar até 1998, quan-

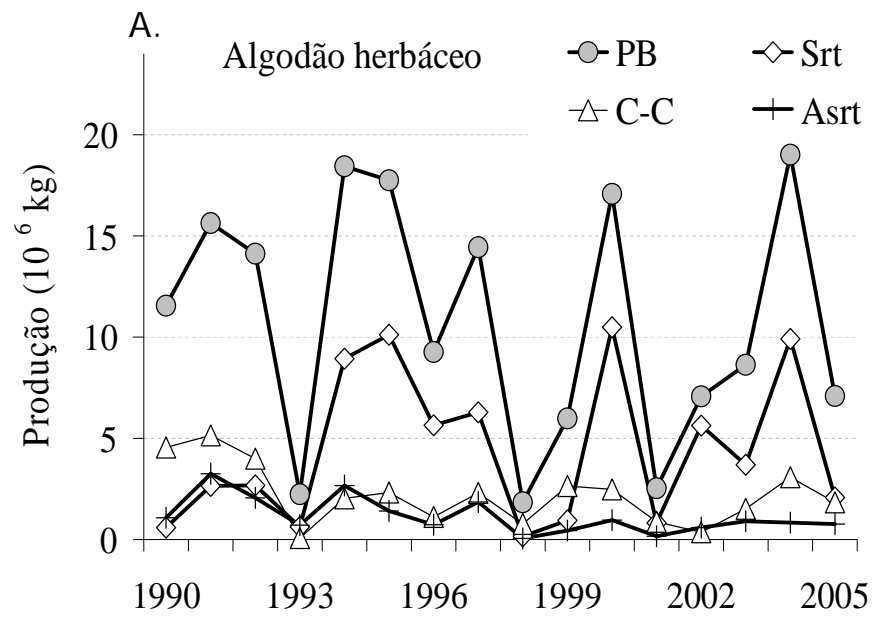

B.

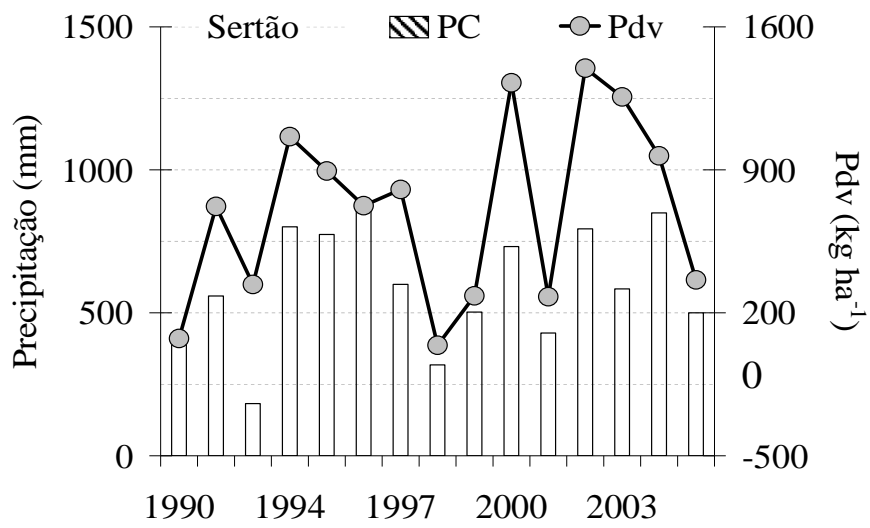

Figura 8. (A) Produção anual de sisal (kg) na Paraíba (PB) e no Cariri/Curimataú (CC). (B) Produtividade (Pdv) anual de sisal $\left(\mathrm{kg} \mathrm{ha}^{-1}\right)$, e a precipitação pluvial (mm) durante o período chuvoso (PC) entre 1990 e 2005 (Fontes: IBGE, 2007 e AESA, 2007) 
do sofreu nova queda, passando para uma produção de aproximadamente 5 mil t ano ${ }^{-1}$ entre 1999 e 2001 e em 2002 atingiu seu menor volume produzido com apenas 4,5 mil t , passando depois a se recuperar levemente, em 2003 e 2004, até alcançar uma produção aproximada de 8,8 mil t em 2005. A queda na produção de sisal está associada, sobremaneira aos efeitos da maior disponibilidade de fibras sintéticas ofertadas no mercado consumidor durante a década de 1990 , que com as variações climáticas. A microrregião do Cariri/Curimataú foi responsável por aproximadamente $84 \%$ de toda a produção de sisal na Paraíba, desde 1990 até 2005. Valores das precipitações pluviais na microrregião do Cariri/Curimataú foram compostos dos totais mensais de sete meses, de dezembro a junho, representando o período chuvoso; valores da produtividade do sisal $\left(\mathrm{kg} \mathrm{ha}^{-1}\right)$ e da precipitação pluvial $(\mathrm{mm})$ para o período chuvoso, na microrregião do Cariri/Curimataú mostraram variações proporcionais entre si, no período de 1990 a 2005 (Figura 8B).

Uma correlação entre a precipitação pluvial do período chuvoso e a produtividade de sisal, resultou em um coeficiente $(r=0,92)$ indicando forte correlação entre a precipitação, durante os sete meses do período chuvoso e a produtividade do sisal na microrregião do Cariri/Curimataú; deste modo, é possível estimar a produtividade do sisal na microrregião do Cariri/Curimataú, através da seguinte equação de regressão polinomial de terceira ordem; $\mathrm{Pdv}=2 \times 10^{-05} \mathrm{PC}^{3}-$ 0,0211 $\mathrm{PC}^{2}+7,3258 \mathrm{PC}-65,295$ (Tabela 2), utilizando-se apenas da informação da precipitação pluvial do período chuvoso que, por sua vez, já se apresentou bem correlacionada com as precipitações dos três meses da pré-estação chuvosa; referida correlação linear indicou que seriam necessários cerca de $500 \mathrm{~mm}$ durante o período chuvoso (210 dias), um volume de chuva em torno de 2 a $3 \mathrm{~mm} \mathrm{~d}^{-1}$ para se obter uma produtividade de cerca de 800 a $1.000 \mathrm{~kg} \mathrm{ha}^{-1}$ de sisal. As estimativas de produtividade agrícolas são importantes ferramentas para o planejamento do cultivo, visando minimizar as possíveis perdas. Os modelos entre as diferentes precipitações e as produtividades das culturas, estão na Tabela 2 .

\section{CONCLUSÕES}

1. Culturas de ciclo longo, como abacaxi e cana-de-açúcar, dependem de outros fatores climáticos; apenas a precipitação não é suficiente para estimar suas produtividades.

2. Há correlações entre as precipitações pluviais ocorridas durante os sete meses do período chuvoso e as produtividades de algodão herbáceo na microrregião do Sertão paraibano, e do sisal, na microrregião do Cariri/ Curimataú.

3. A estimativa da precipitação durante o período chuvoso, obtida através de equação simples, poderá auxiliar na decisão de plantar, ou não, em determinada microrregião, reduzindo o risco de prejuízos na safra agrícola.

\section{LITERATURA CITADA}

AESA - Agência Executiva de Gestão das Águas do Estado da Paraíba. http://www2.aesa.pb.gov.br/meteoro/pcdlmrs.shtml 13 Jun. 2007.

Campos, J. H. B. da C.; Silva, V. de P. R. da; Azevedo, P. V. de; Borges, C. J. R.; Soares, J. M.; Moura, M. S. B. de; Silva, B. B. da. Evapotranspiração e produtividade da mangueira sob diferentes tratamentos de irrigação. Revista Brasileira de Engenharia Agrícola e Ambiental, v.12, n.2, p.150-156, 2008.

IBGE - Instituto Brasileiro de Geografia e Estatística. Sistema IBGE de recuperação automática. Banco de dados agregados. Produção agrícola municipal. 1990-2005. http:// www.sidra.ibge.gov.br/bda/ 20 Jun. 2007.

INPE/CPTEC. Instituto Nacional de Pesquisas Espaciais/Centro de Previsão do Tempo e Estudos Climáticos. El Niño Especial. 2005. http://www.cptec.inpe.br/products/ elninho/ elninho1p.html. 21 Jun. 2007.

IPCC - Intergovernmental Panel on Climate Change. The scientific basis. Houghton, J. T.; Ding, Y.; Nogua, M.; Griggs, D.; Linden, P. V.; Maskell, K. (eds.) Cambridge: University Press, 2001. 892p.

Menezes, H. E. A.; Silva, R. M.; Alves, L. M.; Camargo Jr., H. Análise subjetiva da simulação de precipitação do modelo ETa climático para o Nordeste do Brasil no período entre janeiro e março de 2003. In: Congresso Brasileiro de Agrometeorologia, 13, 2003. Santa Maria. Anais... Santa Maria: SBA, 2003. p.811-812.

Rao, V. B.; Hada, K. Characteristics of rainfall over Brazil: Annual variations and connections with the southern oscillation. Theoretical and Applied Climatology, v.42, n.2, p.81-91, 1990.

Rao, V. B.; Lima, M. C.; Franchito, S. H. Seasonal and interannual variations of rainfall over eastern northeast Brazil. Journal of Climate, v.6, n.9, p.1754-1763, 1993.

Rao, V. B.; Sá, L. D. A.; Franchito, S. H.; Hada, K. Interannual variations of rainfall and corn yields in northeast Brazil. Agricultural and Forest Meteorology, v.85, p.63-74, 1997.

Silva, L. L. Precipitações pluviais da pré-estação chuvosa no período chuvoso e suas influências na produtividade agrícola da Paraíba. Campina Grande: UFCG, 2007. 114p. Dissertação Mestrado

Silva, M. C. L. Uso da técnica dos quantis para monitoramento do clima do Estado da Paraíba. Campina Grande: UFCG, 2004. 33p. Monografia

Silva, M. C. L.; Brito, J. I. B.; Costa, A. M. N. Proposta de monitoramento da precipitação pluvial no Estado da Paraíba utilizando a técnica dos quantis. In: Congresso Brasileiro de Meteorologia, 13, 2004, Fortaleza. Anais...Fortaleza: SBMET, 2004. CD-Rom.

Silva, V. de P. R. da; Guedes, M. J. F.; Lima, W. F. A.; Campos, J. H. B. C. Modelo de previsão de rendimento de culturas de sequeiro, no semi-árido do Nordeste do Brasil. Revista Brasileira de Engenharia Agrícola e Ambiental, v.6, n.1, p.83-87, 2002. 